\title{
Hardware Assessment in Support of the Dynamic Power Convertor Development Effort
}

\author{
Scott D. Wilson ${ }^{1}$, Sal M. Oriti ${ }^{2}$, Nicholas A. Schifer ${ }^{3}$ \\ NASA Glenn Research Center, Cleveland, Ohio, 44135
}

\begin{abstract}
Stirling Radioisotope Power Systems (RPS) are being developed by NASA's RPS Program in collaboration with the U.S. Department of Energy (DOE). Efforts occurring between 2001 to 2015 enabled development of the Technology Demonstration Convertor (TDC) for use in the 110-watt Stirling Radioisotope Generator (SRG-110) and the Advanced Stirling Convertor (ASC) for use in the Advanced Stirling Radioisotope Generator (ASRG). The DOE selected Lockheed Martin Space Systems Company (LMSSC) as the system integration contractor for both flight development efforts. The SRG-110 housed two TDCs fabricated by Infinia and resulted in the production of 16x demonstration units and $2 x$ engineering units. The project was redirected in 2006 to make use of a more efficient and lower mass ASC design under development by Sunpower Inc. The DOE managed the flight contract with LMSSC and subcontractor Sunpower Inc. from 2007 to 2013 to build the Advanced Stirling Radioisotope Generator (ASRG), with support from NASA Glenn Research Center (GRC). Sunpower Inc. held two parallel contracts to produce ASCs, one with Lockheed Martin to produce ASC-F flight units and one with GRC for the production of ASC-E3 engineering unit "pathfinders" that were used to refine the flight design and production processes. The DOE initiated termination of the ASRG contract in late 2013. After ASRG had ended, GRC completed characterization testing of the ASRG Engineering Unit \#2 (EU2) and the GRC contract with Sunpower was also completed. The NASA RPS Program Office has recently initiated a new Dynamic Power Conversion (DPC) development effort to include assessment of several dynamic power conversion technologies for the next generation of RPS. The effort was initiated with the request for proposal and review of submissions. Contracts are anticipated for award in 2017 and will initially focus on a design phase prior to fabrication and testing. This new effort will focus on robustness in addition to high efficiency, specific power, and reliability. Also, some requirements introduced during the ASRG contract have been included in the new effort, such as constant lateral loading. Due to the focus on robustness and new requirements relative to the older TDC design, the Stirling Cycle Development Project has initiated an assessment of government owned hardware to help inform requirements evolution and evaluation of future designs. While lessons learned from the ASRG flight development project have been taken into consideration, the evaluation of the TDC design had not been completed for some existing environments or relatively new requirements. To further assess the TDC design, a series of tasks were initiated to evaluate degradation for units that have operated unattended for over 105,000 hours, demonstrate robustness to a random vibration environment, characterize and evaluate performance for varying lateral load profiles. The status for each task are described.
\end{abstract}

\footnotetext{
ACU $\quad=$ ASC Controller Unit

ASC $\quad=$ Advanced Stirling Convertor

ASRG $\quad=$ Advanced Stirling Radioisotope Generator

DOE = Department of Energy

$(-E 3) \quad=$ Engineering design \#3

(EU2) $\quad=$ Engineering Unit design \#2

${ }^{1}$ Mechanical Engineer, Power Division, 21000 Brookpark Road, M.S. 301-2, Cleveland, OH, 44135.
2 Mechanical Engineer, Power Division, 21000 Brookpark Road, M.S. 301-2, Cleveland, OH, 44135.
${ }^{3}$ Mechanical Engineer, Power Division, 21000 Brookpark Road, M.S. 301-2, Cleveland, OH, 44135.
}

Nomenclature

1

American Institute of Aeronautics and Astronautics 


$\begin{array}{ll}\text { FEA } & =\text { Finite Element Analysis } \\ \text { GPHS } & =\text { General Purpose Heat Source } \\ \text { GRC } & =\text { Glenn Research Center } \\ \text { LMSSC } & =\text { Lockheed Martin Space Systems Company } \\ \text { RPS } & =\text { Radioisotope Power Systems } \\ \text { RTG } & =\text { Multi-Mission Radioisotope Thermoelectric Generator } \\ \text { SCTDP } & =\text { Stirling Cycle Technology Development Project }\end{array}$

\section{Stirling Cycle Technology Development Project}

S tirling Radioisotope Power Systems (RPS) are being developed by NASA's RPS Program in collaboration with $\checkmark$ the U.S. Department of Energy (DOE). An effort ranging from 2001 to 2006 enabled development of the Technology Demonstration Convertor (TDC) for use in the 110-watt Stirling Radioisotope Generator (SRG-110). The DOE selected Lockheed Martin Space Systems Company (LMSSC) as the system integration contractor. LMSSC subcontracted to Infinia to deliver Technology Demonstration Convertors (TDCs) for generator development. The effort resulted in the production of 16x demonstration units and 2x engineering units. The project was redirected in 2006 to make use of a more efficient and lower mass Advanced Stirling Convertor (ASC) for use in the Advanced Stirling Radioisotope Generator (ASRG). The ASC was developed by Sunpower, Inc. through a competitive NASA Research Announcement contract. ${ }^{1}$ The DOE directed LMSSC to subcontract to Sunpower Inc. from 2007 to 2013. Sunpower Inc. held two parallel contracts to produce ASCs, one with LMSSC to produce ASCF flight units and one with GRC for the production of ASC-E3 engineering unit "pathfinders" that were used to refine the flight design and production processes. The DOE initiated termination of that contract in late 2013. Before the ASRG flight contract ended, significant progress was made developing the generator design and enable system level testing. After the contracted ended, GRC completed characterization testing of the ASRG Engineering Unit design \#2 (EU2). ${ }^{2}$ By the end of the GRC held ASC-E3 contract in December 2015, Sunpower delivered 8x ASC-E3s to GRC for testing.

The NASA RPS Program Office has recently initiated a new Dynamic Power Conversion (DPC) development effort through the 2016 Research Opportunities in Space and Earth Sciences (ROSES-16, element C.22) solicitation program with the intent to gather data on candidate dynamic conversion technologies to fill knowledge gaps, support assessments of dynamic conversion technologies, and elicit generator requirements. With the potential to include a variety of power convertor technologies, the effort was initiated with the request for proposal, review of submissions, and contracts are now anticipated for award in 2017. An initial design phase will precede fabrication and testing and the contracts will focus on robustness in addition to high reliability, efficiency, and specific power.

While lessons learned from the ASRG flight development project have been taken into consideration, the evaluation of more mature versions of the TDC had not been completed for some existing environments, like random vibration. Additionally, new critical environments had been introduced since delivery of the TDC hardware, like constant acceleration to account for entry, decent, and landing loads. To further evaluate the TDC design, the Stirling Cycle Development Project initiated an assessment of government owned TDC hardware to help inform requirements evolution and evaluation of future convertor designs. A series of tasks were initiated using existing hardware from SRG-110.

\section{Hardware Assessment}

The TDCs were prototypic technology demonstrators used to mature the technology. There was a total of $16 \mathrm{x}$ TDCs built and tested. ${ }^{3}$ TDCs \#1-\#4 and \#9-\#12 were used for DOE managed development efforts at Infinia, including vibration testing. TDCs \#5-\#8 and \#13-\#16 were provided to GRC for independent verification and validation of the designs under specific test environments, including performance testing and extended operation testing in air and in vacuum. ${ }^{4,5}$ The engineering unit version of the TDC was called the SRG110 Engineering Unit Stirling Convertor Assembly (SES), of which there were 2x units in production and provided to the DOE when the project ended. The SES contained heat acceptor and rejector interfaces designed for the flight generator. The units were later provided to GRC for storage after SRG-110 flight development project ended. Based on an assessment of what hardware was available for these tests and what state that hardware was in, a determination was made to match convertors with each task's objectives. Table I shows the task objectives, hardware used in each evaluation, and status. 
Table I. Summary of Hardware Assessment Tasks

\begin{tabular}{|l|l|l|l|}
\hline \multicolumn{1}{|c|}{ Task Name } & \multicolumn{1}{|c|}{ Objectives } & \multicolumn{1}{c|}{ Hardware } & \multicolumn{1}{c|}{ Status } \\
\hline $\begin{array}{l}\text { Performance } \\
\text { Eegradation }\end{array}$ & $\begin{array}{l}\text { 1-Identify cause of any change in } \\
\text { performance data (facilities vs. } \\
\text { convertor) } \\
\text { 2-Indentify any observable } \\
\text { degredation of convertor interior }\end{array}$ & $\begin{array}{l}\text { TDC \#13 and \#14: } \\
\text { over 105,000 hours of } \\
\text { extended operation }\end{array}$ & $\begin{array}{l}\text { Completed data evaluation, next } \\
\text { step is disassembly of one unit to } \\
\text { enable inspection of internal } \\
\text { surfaces }\end{array}$ \\
\hline $\begin{array}{l}\text { Random Vibration } \\
\text { Testing }\end{array}$ & $\begin{array}{l}\text { fandom vibration loads, observe any } \\
\text { changes in performance based on } \\
\text { pre-test and post-test data }\end{array}$ & $\begin{array}{l}\text { SES \#2, hundreds of } \\
\text { hours of operation }\end{array}$ & $\begin{array}{l}\text { Completed flight acceptance and } \\
\text { launch simulation profiles in } \\
\text { each axis, continued operation } \\
\text { planned }\end{array}$ \\
\hline $\begin{array}{l}\text { Radial stiffness } \\
\text { Evaluation }\end{array}$ & $\begin{array}{l}\text { Evaluate relevant bearing radial } \\
\text { stiffness for varying lateral load } \\
\text { profiles }\end{array}$ & $\begin{array}{l}\text { SES design flexure } \\
\text { bearing springs }\end{array}$ & $\begin{array}{l}\text { Hardware prepared, testing } \\
\text { initiated, model prepared }\end{array}$ \\
\hline $\begin{array}{l}\text { Subject relevant convertor to } \\
\text { constant acceleration loads, observe } \\
\text { any changes in performance based } \\
\text { on pre-test and post-test data }\end{array}$ & $\begin{array}{l}\text { SES \#2, hundreds of } \\
\text { hours of operation }\end{array}$ & $\begin{array}{l}\text { Facilities hardware under } \\
\text { preparation, test planned for } \\
\text { FY18 }\end{array}$ \\
\hline
\end{tabular}

\section{A. Performance Degradation Evaluation}

As of May 17, 2017, TDCs \#13 and \#14 have operated for over 105,620 hours. Performance data have been acquired during this time and various analyses have been performed. There has been no obvious indication of degradation, such as a fast decline in electrical power output or piston amplitude. However, throughout various periods of operation, there have been downward trends in electrical power output. The objectives of this task are to identify the cause of any change in performance data and identify any observable degradation of convertor interior. The data analysis portion has been completed and one unit will be disassembled later this year to complete the second objective.

One example of a downward trends in electrical power output is shown in Figure 1, starting at event \#11. Table II provides a description of each event that coincides to the numbers in Figure 1. During this period that spans approximately 46,000 hours of operation, the electrical power output of each convertor has decreased by $4 \mathrm{~W}_{\mathrm{e}}$. The heater power input during this time span has also fallen, so it was not completely clear if the convertors have degraded, or if the operating point has drifted. Possible causes of operating point drift included a change in cold-end circulator fluid composition change which causes a change in the rejection temperature of the cycle, change in the controller load which causes a change in piston amplitude, and changes in the hot-end thermal insulation which could change the net heat input to the convertor.

Previous efforts to decouple operating point changes from actual convertor performance were inconclusive so a more involved effort was attempted to repeat an operating point in the past as precisely as possible with the current test setup and compare performance of the convertors. The reference operating point identified for this effort was from November 20, 2010 (55,428 hours). This point in time represents a steady state condition that closely follows a circulator fluid adjustment and is sufficiently far away from any other disrupting events.

The operating point is completely defined when one choses the convertor temperatures, working gas mean pressure, piston amplitude, and frequency. Some of these items are measured directly by the test setup instrumentation, and others are a function of direct or intermediate measurement. The hot-end temperature is measured directly by five thermocouples in the heater block on the heater head. These thermocouples have not been altered since the chosen point in time, and were useful for this repeat test. Similarly, the alternator housing temperature is measured directly by three thermocouples and also have not been altered. The cold-end temperature is inferred from the coolant thermocouples and fluid dynamics analysis. This method is sensitive to the composition of the cold-end circulator fluid, which is a mixture of ethylene glycol and water. The mixture is known to vary due to evaporation of the water, which has a large effect on the convertor's operating point. To duplicate the rejection temperature of the cycle, this test had to achieve the same circulator fluid mixture, coolant temperature, and flowrate. The coolant flow rate could have been duplicated by means of the flowmeter, but the flowmeter instrumentation is not of sufficient reliability to use for this purpose. One flow meter reading was lower while the other meter had failed. The fluid composition and temperature were maintained to ensure the cold-end temperature was repeating. 
TDC \#13 \& \#14 Power Output

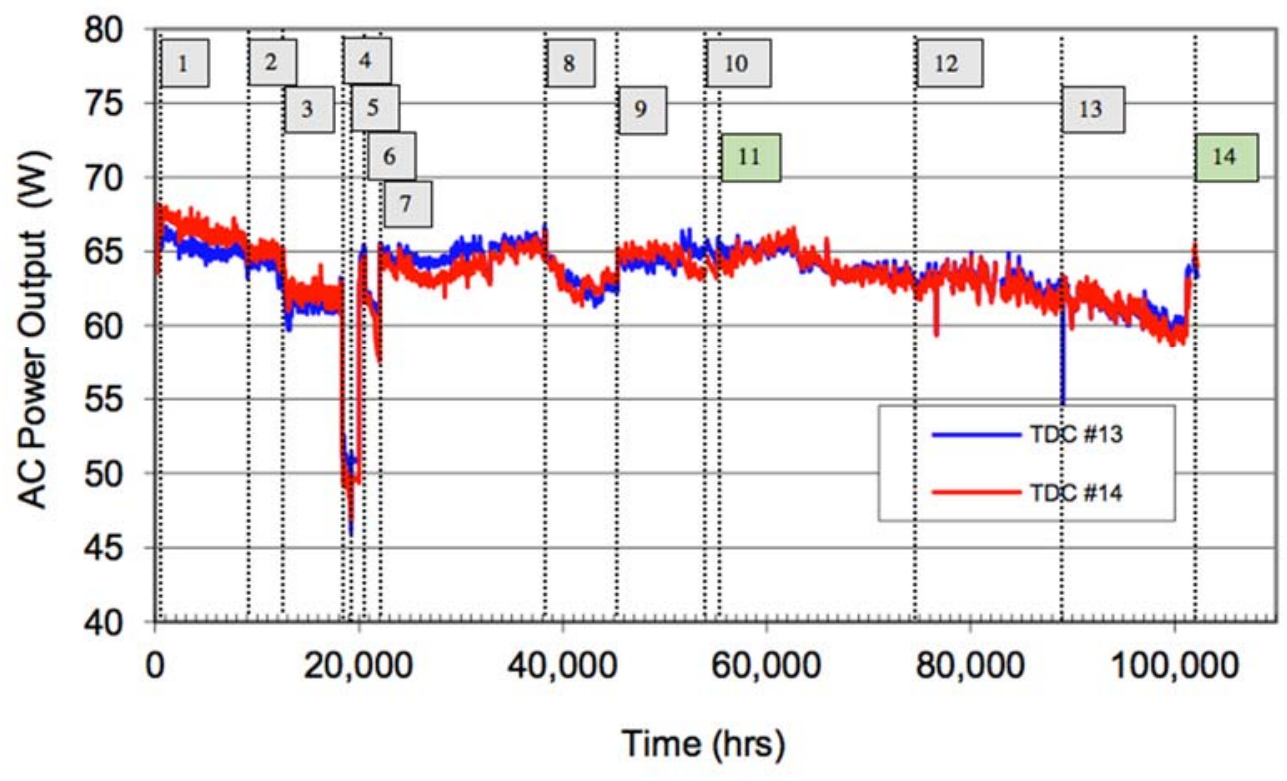

Figure 1. Extended Operation Data for TDC \#13 and \#14 through 102,000 hours.

Table II. Summary of Events for Figure 1.

\begin{tabular}{|c|l|l|}
\hline Event & Hours & Description \\
\hline 1 & 287 & Replaced cartridge heaters \\
\hline 2 & 9,045 & Relocated test stand to R152 \\
\hline 3 & 13,237 & Completed transition back to 100\% EG and adjusted cold-end temperatures \\
\hline 4 & 18,410 & Partial disassembly and inspection, return to operation at low hot-end temperature \\
\hline 5 & 19,107 & Hermetically sealed weld flanges, upgraded insulation to bulk microporous style \\
\hline 6 & 20,023 & Vacuum bakeout, resumed full temperature operation \\
\hline 7 & 22,039 & Replaced cartridge heaters \\
\hline 8 & 37,700 & Series of nuisance shutdowns but no changes in operating point \\
\hline 9 & 45,390 & Piston amplitude adjustment \\
\hline 10 & 54,124 & Replaced cartridge heaters (Sept-2010) \\
\hline 11 & 55,428 & Reference Point (Nov-2010) \\
\hline 12 & 75,000 & Relocated test stand to R158 \\
\hline 13 & 89,000 & Charge pressure adjustment \\
\hline 14 & 101,200 & Repeat reference point (Jul-2016) \\
\hline
\end{tabular}

To repeat the mean charge pressure, a pressure transducer was used with an accuracy of $1 \%$ of reading. The piston amplitude is measured by a Hall-effect sensor that is in the presence of a magnet on the end of the piston's rod. The sensor is non-linear and can't be calibrated after installation so this sensor could be considered less dependable due to potential changes over time, since initial calibration in 2002. The convertor alternator output voltage, current, power, power factor, and operating frequency are all measured by a power meter. There is no direct user control of the operating frequency while using the Zener diode controller, but the frequency is still useful for comparison.

The power output and piston amplitude were matched to the reference point while the heater power needed an additional $1.95 \mathrm{~W}_{\text {th }}$ input on TDC \#13 and only 0.28 watts more input on TDC \#14. This may suggest TDC \#13 is slightly less efficient, however, if this were an actual change in convertor performance, the extra $1.95 \mathrm{~W}_{\text {th }}$ of heater power would account for an additional $0.46 \mathrm{~W}_{\mathrm{e}}$ of alternator power output. This difference is very close to the calculated uncertainty of the alternator power output measurement so it is difficult to know precisely if the same set 
point has been achieved. Also, the hot-end control loop set point had to be adjusted to $3^{\circ} \mathrm{C}$ lower than the reference point to achieve the same average hot-end thermocouple reading. Potential thermocouple drift of these type-K thermocouples may explain the lower set point as these thermocouples have been in place for most of the extended duration test. There will be an attempt to quantify thermocouple drift on at least one unit during the disassembly process later this year. Another possible cause for the lower hot-end control loop set point is potential aging of the microporous insulation, relative to the reference point. However, a 2006 insulation loss characterization test required $56 \mathrm{~W}_{\text {th }}$ to maintain the hot-end temperature at $650{ }^{\circ} \mathrm{C}$ and this test effort's thermal insulation loss characterization required from 55 to $57 \mathrm{~W}_{\text {th }}$ to hold the same hot-end temperature. This result suggests there has been no appreciable change in the thermal insulation.

Table III. Reference Data Compared to Matched Data.

\begin{tabular}{|c|c|c|c|c|c|c|}
\hline \multirow[t]{2}{*}{ Parameter } & \multicolumn{3}{|c|}{$\begin{array}{c}\text { TDC \#13 } \\
\text { (Matched Point) }\end{array}$} & \multirow{2}{*}{$\begin{array}{c}\begin{array}{c}\text { TDC \#14 } \\
\text { (Ref. Point) }\end{array} \\
2010-11-20 \\
11: 59: 59\end{array}$} & \multicolumn{2}{|c|}{$\begin{array}{c}\text { TDC \#14 } \\
\text { (Matched Point) }\end{array}$} \\
\hline & $\begin{array}{c}\text { 2010-11-20 } \\
11: 59: 59\end{array}$ & $\begin{array}{c}2016-08-30 \\
13: 16: 00\end{array}$ & Diff. & & $\begin{array}{c}2016-09-01 \\
12: 00: 00\end{array}$ & Diff. \\
\hline Avg hot-end temp (C) & 640.13 & 640.72 & 0.59 & 640.41 & 640.60 & 0.19 \\
\hline Coolant inlet temp (C) & 59.64 & 59.52 & -0.12 & 59.70 & 59.70 & 0.00 \\
\hline Avg alt. housing temp (C) & 45.61 & 45.90 & 0.29 & 44.10 & 44.17 & 0.07 \\
\hline Ambient temp (C) & 20.53 & 20.37 & -0.15 & 20.53 & 22.17 & 1.65 \\
\hline Mean charge press (psig) & 364.82 & 365.33 & 0.51 & 364.85 & 365.29 & 0.44 \\
\hline Heater power $\left(\mathrm{W}_{\mathrm{e}}\right)$ & 277.40 & 279.36 & 1.95 & 284.19 & 284.47 & 0.28 \\
\hline Piston amplitude (mm) & 5.58 & 5.58 & 0.00 & 5.17 & 5.02 & -0.15 \\
\hline Alternator power $\left(\mathrm{W}_{\mathrm{e}}\right)$ & 65.44 & 65.38 & -0.05 & 64.52 & 64.45 & -0.08 \\
\hline Alt frequency $(\mathrm{Hz})$ & 81.59 & 81.65 & 0.06 & 81.59 & 81.55 & -0.04 \\
\hline Gross efficiency (\%) & 23.59 & 23.41 & -0.19 & 22.71 & 22.66 & -0.05 \\
\hline Controller voltage (vdc) & 85.38 & 86.29 & 0.91 & 85.38 & 85.55 & 0.17 \\
\hline
\end{tabular}

In general, the ability to reconcile small changes in performance data is limited by the precision in which the operating conditions can be set. Some of these effects are quantifiable, while others are not. The most accurate method is to repeat the direct measurements, but even these have uncertainties that cannot be overcome. The hotend thermocouples do not undergo a regular calibration cycle, and their drift in accuracy is not yet quantified. The piston position reading does not have an opportunity for calibration, and still relies on the original calibration from convertor assembly. The cycle's rejection temperature is most difficult to reproduce because it is not measured directly by a sensor. Because the heater power and alternator output power measurements are performed by accurate power meters, and therefore makes the calculation of overall gross conversion efficiency more reliable. In this regard, each convertor's gross conversion efficiency was improved by flushing the coolant plumbing with hot water. The reference point was adequately repeated, as shown by event \#14 in Figure 1 . By the end of the effort to reestablish the reference operating point, each convertor's gross conversion efficiency was slightly lower than the reference point, but only by a fraction of a percentage point.

Over the last 6 years, the gross conversion efficiency has decreased by no more than $0.19 \%$ on TDC \#13 and $0.05 \%$ on TDC \#14. Some or all of this change could be attributed to facility changes, especially the rejection flow system, piston sensor calibration, or thermocouple drift. Some of these sources of uncertainty will be investigated further, during a subsequent disassembly of TDC \#14.

\section{B. Random Vibration Testing}

Flexure-bearing-based Stirling convertors have previously undergone vibration tests. In 1999, TDC \#1 successfully completed a series of vibration tests, including a qualification test up to $12.3 \mathrm{~g}$ rms with a duration of 3 minutes, in three orthogonal axes. In 2004, a similar test was performed on TDC \#9 but the convertor stalled upon reaching launch level in the lateral axis due to regenerator fibers obstructing the displacer motion. It was determined that TDC \#9's operational history compromised the regenerator in such a way to create a failure mode that would not normally be present in a flight convertor. This test is intended to further supplement the prior TDC tests. The task objective was to subject a relevant convertor to updated random vibration loads and monitor for changes in performance based on pre-test and post-test data. Survey of available hardware identified the engineering units, which have flight interfaces and a flight regenerator design. SES \#2 was chosen for this test and removed from storage in 2016 for this test. The SES \#2 was revalidated via a pneumatic test and an operational checkout test at full power. A vibration fixture was custom designed for this convertor, and designed to have a first natural 
frequency greater than $1900 \mathrm{~Hz}$, which is proper for the planned vibration test profile of 20-2000 Hz. Figure 2 shows the top view of the SES \#2 installed into the vibration fixture and the random vibration profile used in this test. The profile was formulated by combining the greater of JPL's multi-mission profile for flight acceptance, used on the Multi-Mission Radioisotope Thermoelectric Generator (MMRTG), and that of the NASA Goddard's General Environmental Verification Standard (GEVS) specification for flight acceptance testing. ${ }^{6}$ This test simulated the flight processing of a convertor, including flight acceptance for a duration of 1 minute, and then an actual launch, with a duration of approximately 1 minute. This test combined the two events into an exposure to launch vibration loads for a duration of 2 minutes for each of the three orthogonal axes. The original pressure vessel that was installed on the SES, as delivered to the government was longer and contained a quartz window for piston sensor calibration. The pressure vessel needed for this test is shorter, contains a dome where the quartz window was, and contains a mounting flange. It was designed at GRC, based on a combination of drawings made available from the flight development project. The isolation valve was hard mounted to the fixture (not shown) and the electric heat source was loaded against the heater head using a loading mechanism that provides the $350 \mathrm{lb}$ load at temperature. The LVDT signal is only valid near the in-end extent of piston motion. It was designed to function as a proximity warning sensor for a flight control application during the SRG110 project. Prior to the vibe test, this sensor was calibrated to a laser position senor, so that piston amplitude could be inferred from it.

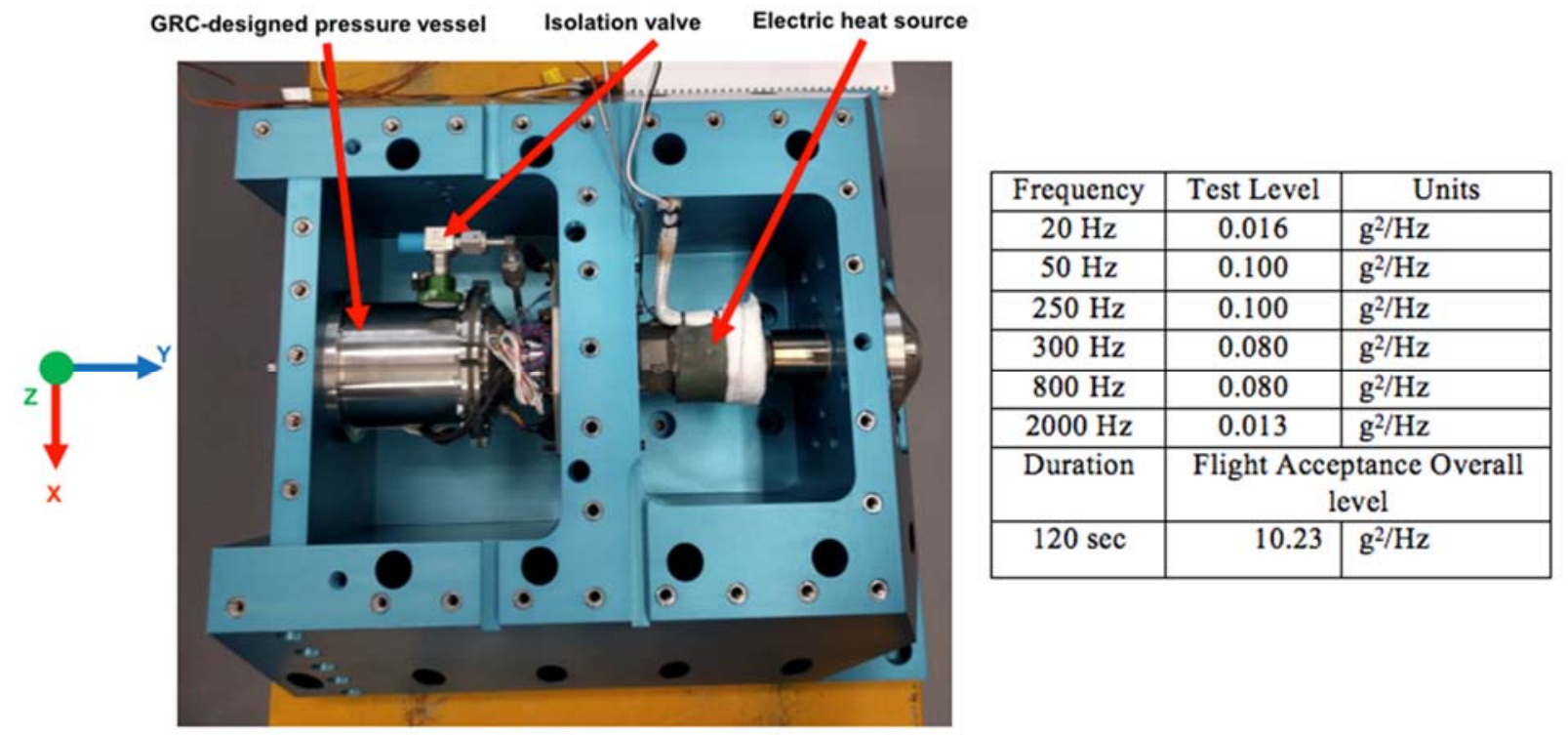

Figure 2. Random vibration fixture (left) and Acceleration Spectral Density profile used in test (right).

The convertor was operated during testing and survived the 3-axis random vibration exposures, simulating the combined effect of flight acceptance testing and launch. There were small differences in the convertor's power output before and after some random vibration exposures, that are thought to be due simply to changes in the structural connection between the test article and Earth. In the y-axis case (axial is in-line with piston motion), there was a $1.4 \mathrm{~W}_{\mathrm{e}}$ decrease in the convertor's power output. Just prior to the first random vibration exposure attempt, the convertor's power output was $67 \mathrm{~W}_{\mathrm{e}}$. During the first axial attempt, the beginning operating point was at the baseline piston amplitude of $5.9 \mathrm{~mm}$. A warning cursor was set up on an oscilloscope to represent a point $0.3 \mathrm{~mm}$ away from the physical limit of piston motion, and corresponds to a piston amplitude of $6.7 \mathrm{~mm}$. Another curser was set up to represent physical collisions between the piston bumper and hard stop. It was agreed upon for this test that collisions would be grounds for abort and piston excursions exceeding the warning cursor would be evaluated real time based on level and frequency. During the first axial attempt, numerous piston excursions were occurring that exceeded the warning cursor, even at the $-6 \mathrm{~dB}$ level. Two of the excursions even appeared to exceed the hardstop cursor. The attempt was aborted and the table was stopped to decrease the piston amplitude and allow temperatures to settle. The piston amplitude was then reduced by $1 \mathrm{~mm}$ to $4.8 \mathrm{~mm}$, which brought the convertor's power output to $43 \mathrm{~W}_{\mathrm{e}}$. The random exposure was then successfully completed, up to full level $(0 \mathrm{~dB})$. During the $\mathrm{y}$-axis full-level exposure, the convertor's power output varied between $54.3 \mathrm{~W}_{\mathrm{e}}$ and $22.2 \mathrm{~W}_{\mathrm{e}}$. During the 2 minutes at full level, there were 14 piston motion excursions that exceeded the warning cursor but were thought to be

6

American Institute of Aeronautics and Astronautics 
acceptable so the test was completed. After the shaker table was halted, the piston motion returned to its stable state as just prior to the exposure. Figure 4 shows the response from accelerometers located on the CSAF and pressure vessel (aka. alternator housing).

In preparation for the second axis, the piston amplitude was increased back to the baseline value of $5.9 \mathrm{~mm}$ and time was spent allowing conditions to return to steady state. The convertor's power output returned to $65.6 \mathrm{~W}_{\mathrm{e}}$, instead of the $67 \mathrm{~W}_{\mathrm{e}}$. The lower power could be caused by slight variances in the shake table stiffness or due to magnetic fields of the table actuator.

. Only minor temperature changes were observed at that time that would not account for the difference in power output. Before the test had started, the state of the shaker table hydraulic pump and the state of the shaker's magnetic field disrupted the convertor power output by up to $1 \mathrm{~W}_{\mathrm{e}}$. It is hypothesized that the mass of the fixture and the shaker table are not enough to reduce residual case motion of the convertor to a low enough level that the dynamics are unaffected. During the first lateral axis, further evidence of the sensitivity of convertor operation to mounting stiffness and structural mass was revealed during the time the fixture was being rotated from the y-axis to the $x$-axis. During this time, the fasteners holding the fixture to the shaker table were loosened, the test article was lifted off of the table with the overhead crane so it could be rotated $90^{\circ}$, all while the convertor continued to operate. The state of the fasteners and state of the fixture resting on the table had a sizeable effect on the convertor's power output, on the order of $3 \mathrm{~W}_{\mathrm{e}}$. The convertor's power output was $65.8 \mathrm{~W}_{\mathrm{e}}$ just prior to the $\mathrm{x}$-axis random exposure. After conditions returned to steady-state following the $\mathrm{x}$-axis exposure, the convertor's power output was $65.7 \mathrm{~W}_{\mathrm{e}}$, indicating negligible change in convertor performance. The application of lateral random vibration did cause a temporary reduction in convertor power output due to potential contact between the piston and cylinder or the displacer and its rod, areas where running clearances are designed to be as small as possible. The minimum power output observed was $35.5 \mathrm{~W}_{\mathrm{e}}$. Further, there were still piston motion excursions that exceeded the warning curser, at least one instance of the signal reaching the hard-stop cursor. Even though the lateral vibration introduced piston motion increases above nominal, the overall trend was a reduction in convertor power output. Operation was then shut down to prepare for moving of the test article up onto the z-axis shaker table.

During the second lateral axis, the operating point established in this axis was not the same as the $\mathrm{y}$ and $\mathrm{x}$ axes. The starting point power output was only $60.7 \mathrm{~W}_{\mathrm{e}}$, even though the user-adjustable parameters were set to the same values as the baseline operating point. The z-axis table, shown in Figure 3, is significantly lighter than that used for the $\mathrm{X}$ and $\mathrm{Y}$ axes. It is possible this permitted more residual case motion, and disrupted sensitive displacer motion, such that the power output was reduced relative to the baseline operating point. The application of random vibration in this axis had an effect similar to that of the x-axis. The convertor's power output was temporarily reduced, due to intermittent rubbing of the moving components. The minimum power output observed was $34.9 \mathrm{~W}_{\mathrm{e}}$. The convertor power output returned to normal after the shaker table was stopped. After completion of the post z-axis sine sweep, there were a few curious increased in the convertor power output. These could have been due to some change in the state of the shaker table, as was observed in the previous axes. During this exposure, there were also piston motion excursions. Three such excursions exceeded the warning cursor but none reached the hard-stop cursor.

The consequence of these test result is that the piston amplitude may require a reduction command from the controller to avoid collisions due to piston motion excursions during the launch environment. Such a requirement could be permitted, and must be considered during system integration trade studies and concept of operations formulations. It should also be noted that the type of controller used here, the AC bus method with a physical tuning capacitance, may not be ideal for holding back piston motion excursions. Previous vibrations tests on other convertors revealed that adjustments to the tuning capacitance value had an effect on the size of the piston motion excursions. Further analysis and testing is required to investigate this possibility for the SES design. 


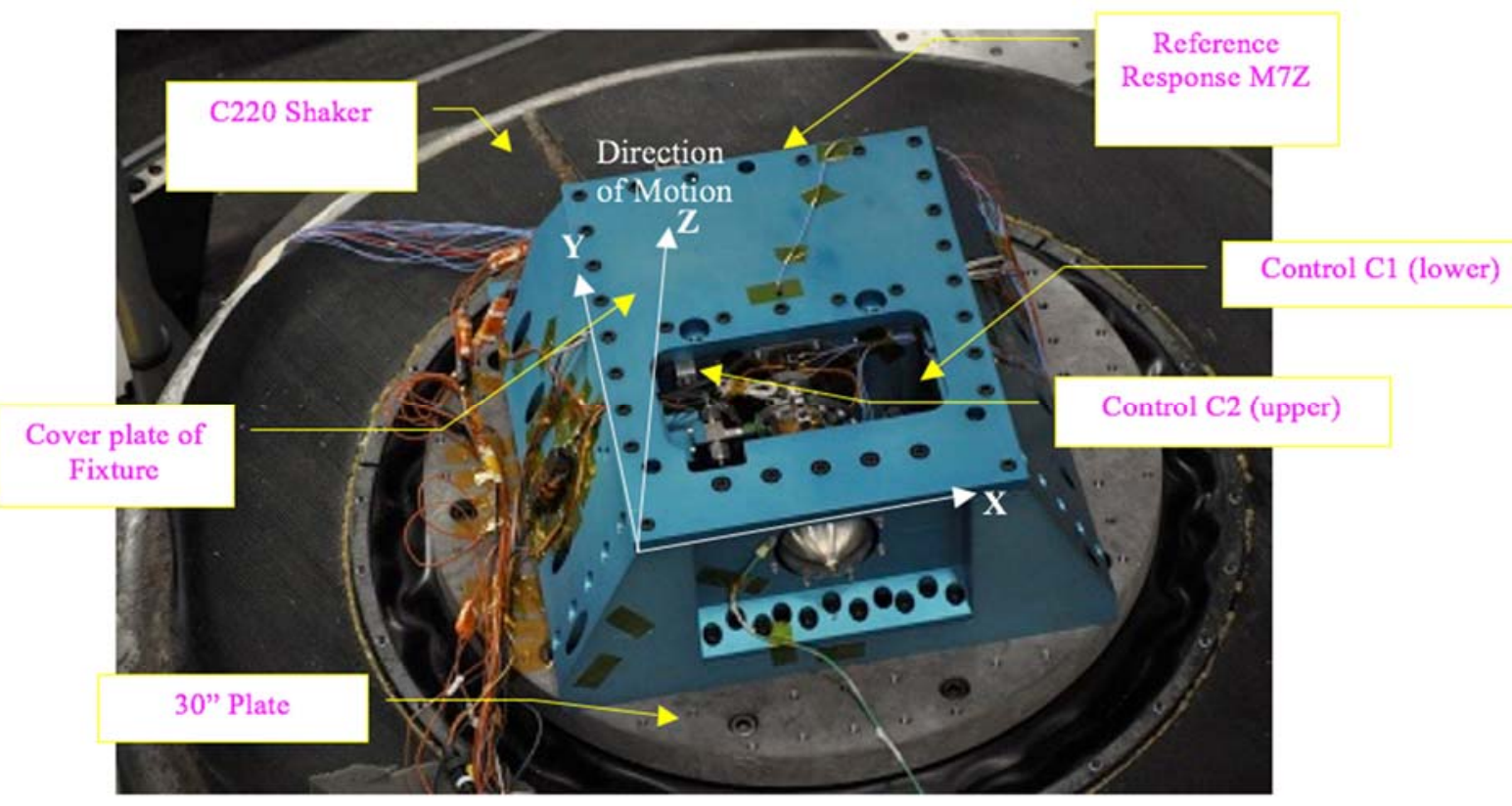

Figure 3. Random vibration fixture (left) and Acceleration Spectral Density profile used in test (right).

Table IV. Measured grms levels from Flight Acceptance \& Launch Simulation Random Vibration Test.

\begin{tabular}{|c|c|c|c|}
\hline Axis & Control Average & CSAF Response & Pressure Vessel Response \\
\hline $\begin{array}{c}\text { Y-Axis (Axial) Flight Acceptance } \\
\text { \& Launch Simulation }\end{array}$ & $10.21 \mathrm{grms}$ & $12.71 \mathrm{grms}$ & $16.52 \mathrm{grms}$ \\
\hline $\begin{array}{c}\text { X-Axis (Lateral) Flight Acceptance } \\
\text { \& Launch Simulation }\end{array}$ & $10.15 \mathrm{grms}$ & $10.92 \mathrm{grms}$ & $11.54 \mathrm{grms}$ \\
\hline $\begin{array}{c}\text { Z-Axis (Lateral) Flight Acceptance } \\
\text { \& Launch Simulation }\end{array}$ & $10.27 \mathrm{grms}$ & $12.65 \mathrm{grms}$ & $17.22 \mathrm{grms}$ \\
\hline
\end{tabular}

grms responses are those calculated from the NX I-deas Time History data collected on the B\&K-LAN-XI System
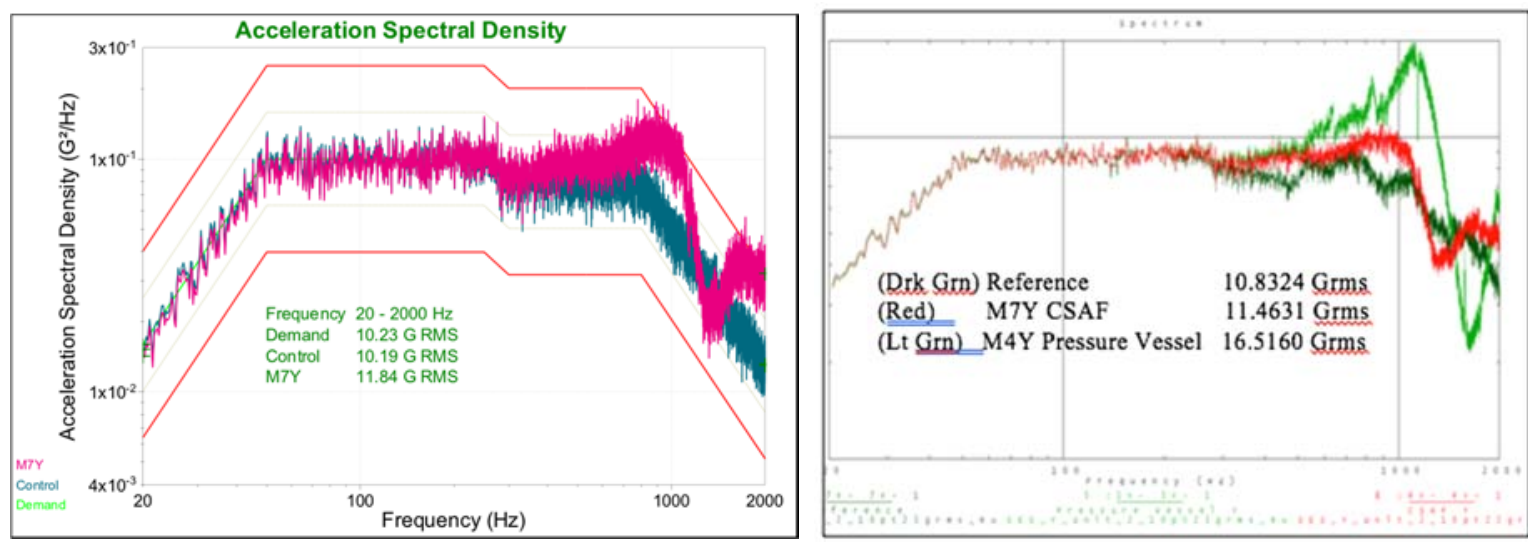

Figure 4. CSAF \& Pressure Vessel Response; Y-Axis Flight Acceptance \& Launch Simulation Test. 


\section{Radial Stiffness Evaluation}

Radial stiffness testing was pursued to assess the piston and displacer flexure bearing radial stiffness for relevant TDC designs and compare stiffness against the relatively new $5 \mathrm{~g}$ load requirement for future Stirling convertors. The TDC convertors use flexure bearings, which have a high radial stiffness relative to their lower axial stiffness, to provide non-contact operation. The TDC flexure bearings have accumulated over a decade of operation with $1 \mathrm{~g}$ of radial loading, including 105,000 hours (12 years) of operation on TDC \#13-\#14 and 95,000 hours (10.8 years) of operation on TDC \#15-\#16. This task will help identify the level of static radial g-loading the TDC flexures can tolerate before the moving components begin to rub. Also, the test rig will be used to characterize future designs for radial stiffness and help validate FEA models.

The approach taken in this effort was to use analytical modeling to predict the radial stiffness at zero axial deflection, and then compare the prediction to empirical test results acquired using available spare TDC flexures. The empirical results could then be used to understand modeling errors and potentially make model revisions to better match analysis results to test data. These revised models could then be evaluated under increasing radial loading conditions. The radial load would be incrementally increased until a component of the moving piston or displacer assembly is deflected enough to make contact with a static component.

Individual Finite Element Analysis (FEA) models of a single piston and a single displacer flexure were developed in COMSOL. These models were used to predict the maximum radial deflection and load before yielding, and these results were used with a safety margin of $12.5 \%$ to set a maximum deflection limit for the physical tests. The FEA models were also used to predict the radial stiffness of each of the flexures. The preliminary test results of a single piston flexure indicated a model over prediction for the radial stiffness of $16.3 \%$ at an axial deflection of zero. This over prediction was expected and is typical for this type of analysis. The preliminary test results were used to develop a test plan for more springs. It is planned to apply the average over prediction value as a correction factor in the modeling effort. It was observed in the modeling that the radial stiffness decreases as axial deflection increases, as can be seen in Figure 7. There are no current plans to verify this relationship via testing, rather it will be assumed this relationship is valid and that the correction factor remains the same as the flexure is deflected from zero to full amplitude.

A simple test fixture for measuring the radial stiffness of the TDC flexures at zero axial deflection has been prepared for radial stiffness testing. The test rig, shown in Figure 8, works by constraining the inner diameter hole of the flexure while forcing displacement of the outer diameter of the flexure. The flexure is fastened at the outer bolt pattern between two aluminum plates with the same washers used in engine assembly to provide spacing and the appropriate surface area. A precision ground load bearing pin fits through the center hole of the flexure and is supported by two fixed aluminum plates. A load is then applied to the top of the flexure assembly by tightening a lead screw, which transmits the load through a thrust bearing assembly with a load cell to measure the force. The deflection is measured via a laser displacement sensor. The flexures were then incrementally displaced by 0.1 $\mathrm{mm}$ increments and the force was recorded. This process was repeated in multiple orientations on the same flexure and the calculated stiffness was averaged. Preliminary data from the test rig measured an average stiffness of the piston flexure at $49.5 \mathrm{lbf} / \mathrm{mm}$, a value that is consistent with the design.

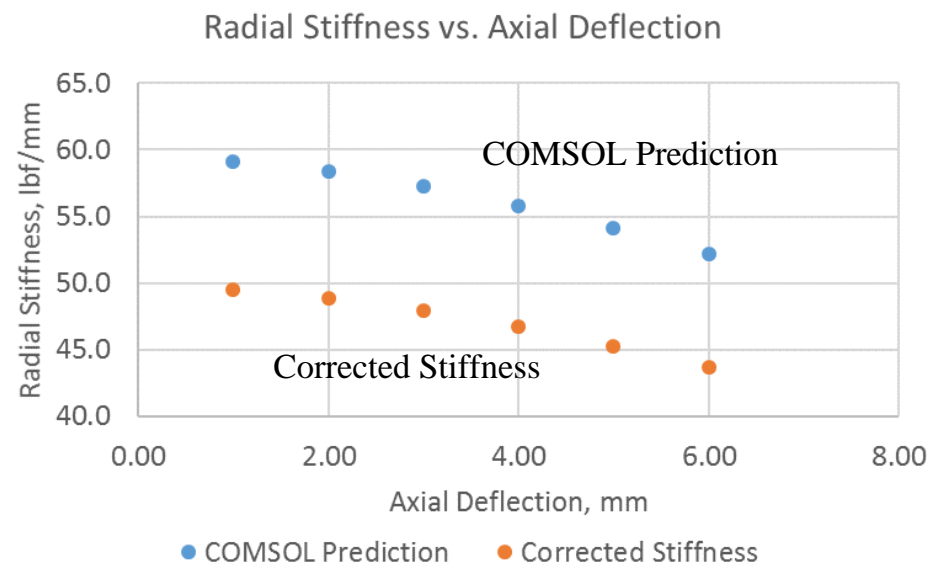

Figure 7. Relationship of piston flexure radial stiffness to axial deflection. 
The effort also included creation of an FEA model to investigate deflection of the piston and displacer subassemblies, while under increasing radial loads. Currently, only the piston sub-assembly has been modeled; however, a similar process will be employed to create the displacer subassembly model. In order to reduce the number of elements and the computational time, the piston assembly model was simplified by removing several components from the subassembly and applying mass boundary conditions at those locations. The flexures were also simplified to "spring foundation" boundary conditions at locations where flexure stacks contact the piston rod. This enabled the stiffness to be adjusted to the corrected value, based on test data. With the proper mass distribution and support stiffness, the deflection of the piston rod was monitored at critical close clearance locations to determine maximum tolerable g-loading before contact. Preliminary model results indicate that first contact of the piston assembly will occur for the piston and cylinder running clearance at approximately 4.3g. These preliminary results will be confirmed with additional modeling and test data.

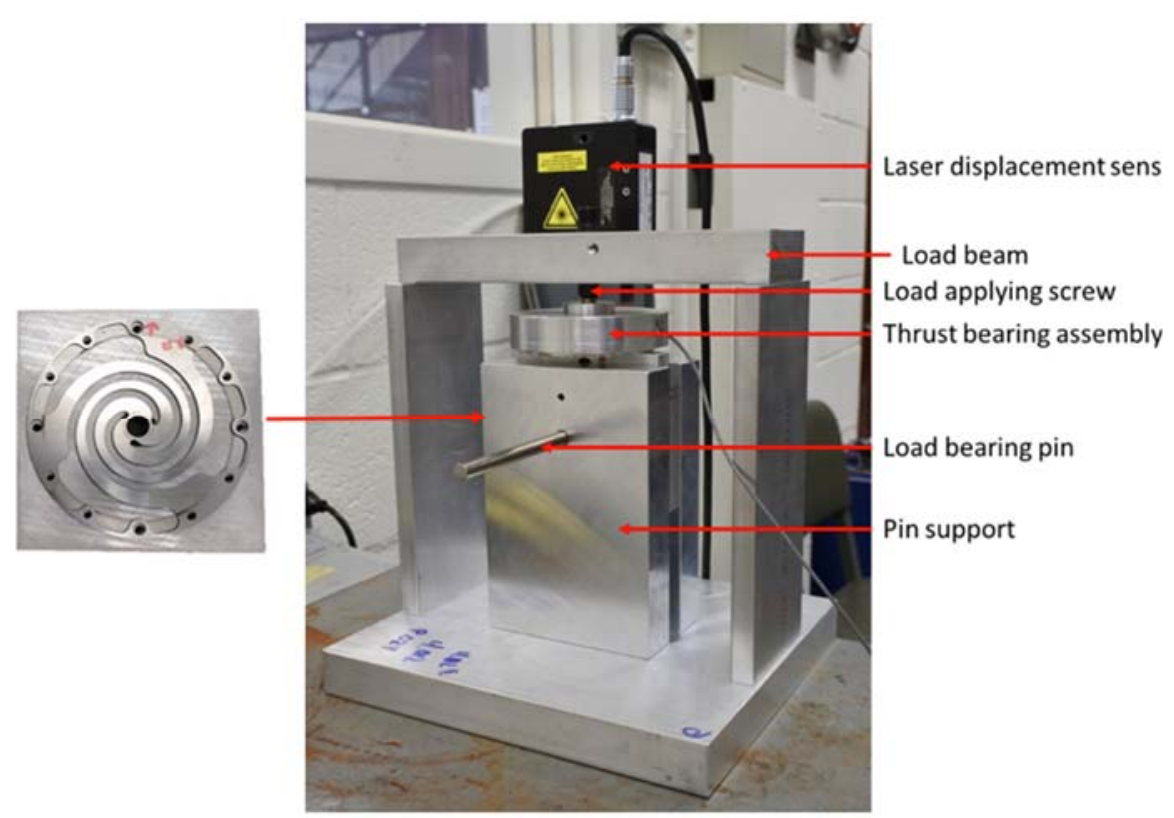

Figure 8. Flexure holding plate (left) and Radial Stiffness Test Rig (right).

\section{Constant Acceleration Testing}

Exposure to the constant acceleration environment was added to ASRG requirements during that flight development project. The project subjected an ASC to the $18 \mathrm{~g}$ constant load in three orthagonal axes. ${ }^{7}$ The objective of this effort will be to subject a relevant TDC convertor to constant acceleration loads and observe any changes in performance based on pre-test and post-test data.

Similar to the random vibration task, a survey of available hardware identified SES \#2 as the most relevant hardware on which to perform this test. Similar to the radial stiffness test effort, this test is meant to assess the radial stiffness of the piston and displacer flexure bearings for increasing lateral load values and confirm robustness against conditions that will certainly cause contact between the piston and cylinder or the displacer and its rod. The TDC convertors use flexure bearings, which have a high radial stiffness relative to their lower axial stiffness, to provide non-wear operation. The test is being prepared for completion in FY18 at Case Western Reserve University (CWRU), where the ASC constant acceleration test was performed. Figure 9 shows an image of the centrifuge arm, bucket that holds the test article and swings out as the arm gets up to speed. The convertor will be mounted to the bucket inside a holding fixture.

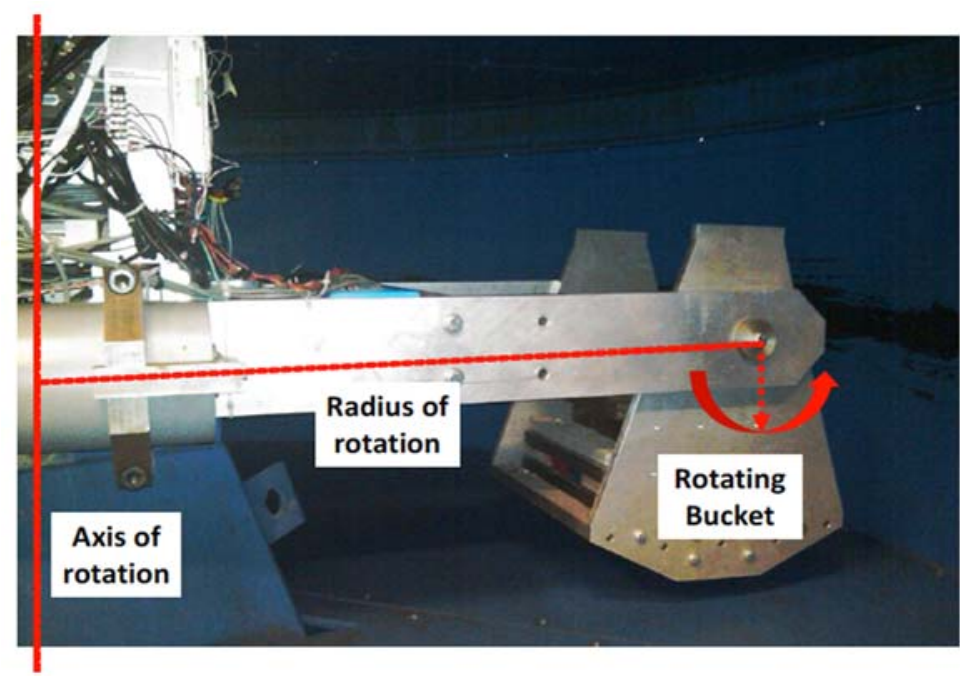

Figure 9. Centrifuge Test Facility at CWRU in Cleveland.

American Institute of Aeronautics and Astronautics 


\section{Conclusion}

The NASA RPS Program Office has recently initiated a new Dynamic Power Conversion (DPC) development effort through the 2016 Research Opportunities in Space and Earth Sciences (ROSES-16) solicitation program, with the intent to gather data on candidate dynamic conversion technologies to fill knowledge gaps, support assessments of dynamic conversion technologies, and elicit generator requirements. While lessons learned from the ASRG flight development project have been taken into consideration, the evaluation of more mature versions of the TDC had not been completed for some existing environments. To further evaluate the TDC design, the Stirling Cycle Development Project initiated an assessment of government owned TDC hardware to help inform requirements evolution and evaluation of future convertor designs. A series of tasks were initiated using existing hardware from SRG-110, including assessment of performance degradation, robustness to the random vibration environment, characterization of flexure bearing radial stiffness, and robustness to the constant acceleration environment. So far, the assessment of performance degradation task has completed analysis of test data and has concluded that the gross conversion efficiency has likely decreased due to facility set point drift and by no more than $0.2 \%$. The robustness to the random vibration environment, under flight acceptance and launch simulation profiles, was successfully verified using an engineering unit from SRG-110. Preliminary results have been acquired for characterization of flexure bearing radial stiffness under varying constant load profiles. Finally, hardware is being prepared to assess robustness under a constant acceleration test environment in the next fiscal year.

\section{Acknowledgments}

This work is funded through the NASA Science Mission Directorate and the Radioisotope Power Systems Program Office. Any opinions, findings, conclusions, or recommendations expressed in this article are those of the authors and do not necessarily reflect the views of NASA.

\section{References}

${ }^{1}$ Wong, W.A., Wilson, S.D., Collins, J., Wilson, K., "Advanced Stirling Convertor (ASC) Technology Maturation", Proceedings of the $13^{\text {th }}$ International Energy Conversion Engineering Conference (IECEC), AIAA, Orlando, FL, July 2015.

${ }^{2}$ Oriti, S.M., "Advanced Stirling Radioisotope Generator Engineering Unit 2 (ASRG EU2) Final Assembly”, Proceedings from the 2015 Nuclear and Emerging Technologies for Space, Albuquerque, NM, 2015.

${ }^{3}$ Schreiber, J.G., "Status of the NASA Stirling Radioisotope Project", NASA/TM-2007-214804, NASA Glenn Research Center, Cleveland, OH, 2007.

${ }^{4}$ Oriti, S.M., "Extended Operation of Stirling Convertors in a Thermal Vacuum Environment", Proceedings from the 3rd International Energy Conversion Engineering Conference, San Francisco, CA, August 2005.

${ }^{5}$ Schreiber, J.G.; and Thieme, L.G., "GRC Supporting Technology for NASA's Advanced Stirling Radioisotope Generator (ASRG)”, NASA/TM—2008-215196, NASA Glenn Research Center, Cleveland, OH, 2008.

${ }^{6}$ NASA Goddard Space Flight Center, "GENERAL ENVIRONMENTAL VERIFICATION STANDARD (GEVS) For GSFC Flight Programs and Projects”, GSFC-STD-7000, April 2005

${ }^{7}$ Meer, D.W., Oriti, S.M., "Advanced Stirling Convertor Durability Testing: Plans and Interim Results", NASA/TM—2012-217727, NASA Glenn Research Center, Cleveland, OH, 2012. 